\title{
Narrative Personality Psychology: A new tool for fueling professional women's success and well-being
}

\author{
Cynthia E Winston-Proctor $\mathrm{PhD}^{1 *}$ and Lisa Winston Hicks JD ${ }^{2}$ \\ ${ }^{1}$ Howard University Department of Psychology, Washington DC, USA \\ ${ }^{2}$ Kalmia Partners LLC, Dallas, Texas, USA
}

Submission: September 14, 2020; Published: October 30, 2020

"Corresponding author: Cynthia E Winston-Proctor, Howard University Department of Psychology, Washington DC, USA

\begin{abstract}
Following a brief introduction to the burgeoning field of narrative personality psychology, the authors offer a novel theory: organizations can apply narrative personality psychology to promote well-being and success, particularly among professional women. Using scientific and statistical research, the authors encourage organizations committed to the retention and career advancement of women to explore new narrative personality psychology models to harness the investments they are already making in diversity \& inclusion, leadership development, talent development and employee wellness.
\end{abstract}

Keywords: Organizational psychology; Narrative psychology; Personality psychology; Diversity \& inclusion; Culture; Women; Workplace

\section{A New Conversation about Women in the Workplace}

With her book Lean In: Women, Work, and the Will to Lead [1], Sheryl Sandburg, COO of Facebook, prompted a seismic shift in the contemporary conversation about professional women's identity and psychology of success. Sandburg [1] argued that though women face many external barriers that limit their ascendency to senior leadership positions in the workplace (e.g. blatant and subtle sexism, sexual harassment, lack of sponsorship), they also hold themselves back from achieving greater career success. More specifically, Sandberg highlights as self-limiting obstacles to advancement in the workplace: lack of self-confidence, reluctance to volunteer or ask for stretch opportunities, "pulling back vs. leaning in", competing family priorities, and limited aspiration to senior leadership positions. That perspective generated avid support and sharp criticism, becoming "the" cultural conversation until \#MeToo came roaring along to supplant it [2]. However, at the peak of interest in Lean In, Sandburg thoughtfully deployed her book as a foundation for more than 40,000 women in over 170 countries to gather in 'Lean In Circles' to share stories and think critically about their personal, workplace, and family life experiences.

\section{The Paradox of Women's Educational and Workplace}

\section{Experiences}

Sandburg's book and her Lean In Circles created a safe space to discuss a paradox many had quietly observed. Why do women, now better educated and with more professional experience than ever before, still lag far behind their male peers in executive leadership roles? Moreover, why is "having it all" no longer the aspiration for millions of women whose mothers paved the way for it? In this article, we explore some of the reasons for the persistent gender gap in executive leadership roles and describe how organizations committed to retain and promote qualified women can use narrative personality psychology models to more effectively meet their goals.

\section{Women are Better Educated and Outnumber Men in}

\section{Today's Professional Workforce}

Let's start with the data. In the United States, women are more educated and represented in the professional workforce than at any other time in history. Based on national reports issued in 2017 and 2018, women in the US earn almost 60 percent of 
bachelor's and master's degrees and approximately 50 percent of MBAs, law degrees, and doctorates: $57 \%$ of bachelor's degrees [3], 59.2\% of master's degrees [4], $53.5 \%$ of doctoral degrees [4], 48\% of master's in business administration (National Center for Education Statistics, Table 325.25 nces.ed.gov); and 47.2\% of law school degrees (American Bar Association). These women with undergraduate, graduate, and professional degrees are then flowing into the workforce. In 2016, women comprised 52 percent of all workers employed in management, professional, and related occupations, somewhat more than their share of total employment (47 percent) [5].

\section{Yet, Women are not Advancing to Leadership Positions in the Same Way as Their Male Peers}

Despite educational achievement and preliminary career placement among women, profound differences exist between male and female career advancement and satisfaction in the workplace [6,7]. Across corporate, government, and academic work sectors, women are not advancing to executive leadership positions at a rate that is even close to that of men of comparable education and professional experience. For example, the largest comprehensive study of the state of women in corporate America, a project that included 279 companies employing more than 13 million people, found that women were disadvantaged from the very start of their careers [8]. More specifically, the study found that "although women earn more bachelor's degrees than men, they are less likely to be hired into entry-level corporate jobs. At the first critical step up to manager, the disparity widens further. Women are less likely to be hired into manager level jobs, and they are far less likely to be promoted into them. As a result, men end up holding $62 \%$ of manager positions, while women hold only $38 \% "$ [8]. Gender disparities grow even greater at the highest levels, with women comprising $23 \%$ of C-Suite executives among the 279 corporations surveyed. Women of color account for only $4 \%$ of those C-suite jobs [8].

\section{Persistent Gender Disparitiesin Payand Responsibilities}

On average in the United States, professional women earn 81 cents for every dollar paid to their male peers [5]. While identifying the reason for the gender disparity is beyond the scope of this article, there is research to suggest a childbearing and childrearing "penalty" for working women:

“... the persistent wage gap between men and women is due mainly to the penalties women incur when they interrupt their careers to have children. In a recent study, economists Susan Harkness and Jane Waldfogel compared that wage gap across seven industrialized countries and found it was particularly wide in the United States. . . .These days, only a small portion of this wage gap can be attributed to discrimination (getting paid less for doing the same job or being denied access to jobs, education, or capital based on sex). According to recent studies, an increasingly large part of the wage gap can now be explained by childbearing and child rearing, which interrupt women's-but not men'scareers, permanently depressing their earning power" [9].

In addition to long term pay disparities in the workplace, the gender gap is also felt at home. "Women face all the challenges that men do in working long hours and withstanding the up-or-out pressures of high-altitude careers. But they also face challenges all their own" [9]. Among the challenges noted by Hewlett [9]. and others is that professional women continue to be responsible for most work in the home including chores, family spending, and daily meals. In fact, women are generally. shouldering significantly more of household work than men. A 2018 report from the United Nations found that women are shouldering nearly three times more of the work associated with the home than men - childcare, elder care, cooking, cleaning, transportation - and usually for zero pay. This, even though more people than ever view men and women as equal in the workplace and in the home" $[10,11]$. It seems perception and the real world don't always match up. Within a women's personal life this psychological and physical burden results into what some have called "unpaid care". For example, Gaëlle Ferrant, Luca Maria Pesando and Keiko Nowacka (2014), describe unpaid care as "the missing link in the analyses of gender gaps in labour outcomes (p. 1)". Women are also often the "default" parent responsible for handling routine needs, conflicts, unexpected schedule changes, and emergencies within their families. Scholars have labeled the work that women perform at home as "invisible labor" [12].

\section{Stress!}

There is mounting scientific evidence that disproportionate responsibilities at home exacerbate stress within women's lives [12]. Stressors accumulate because of competing and often conflicting responsibilities that demand time and mental energy at work and home. Research demonstrates that women are less likely than their male peers to feel satisfied with their career or professional choices because of the competing home demands $[13,14]$. Also, women report financial strain as a major stressor in their lives (Kraft, 2017). And recall that women are earning less as they try to balance work and childbearing.

There are two different types of stress, each with distinctive characteristics and impact on women's lives.

Acute stress is short-term stress (e.g. having a disagreement with your boss about a project at work); psychologists also refer to these kinds of stressors as "daily hassles". Within the human body's elegant design is a natural response to any kind of threat, including acute stress. Thus, all humans have an automatic physiological response to stress that has become known among scientists as the fight or flight reflex. This automatic stress response triggers biochemical reactions in the brain and other parts of the body [15]. Clinical health psychologist Dr. Denee Thomas Mwendwa's behavioral health research [16-18] starts with a premise that is simple, yet profound: stress is part of the human experience and 
therefore, unavoidable. This is an important scientific fact that rarely is part of the discussion about managing stress within women's lives. More often than not the emphasis on stress is how to eliminate it. This is simply physiologically impossible. Acute stress. it is only one half of the stress story within women's lives.

In contrast to acute stress, chronic stress is long-term stress. Examples of chronic stress for women include stress caused by prolonged experiences of men taking credit for their innovative ideas or working in a toxic work environment characterized by subtle forms of sexual harassment (e.g. sexual jokes, images, and comments). And there is considerable evidence that chronic stress has high costs for not only individuals, but also organizations. Workplace stress, which can include acute and chronic, accounts for nearly $\$ 200$ billion in health care costs annually [19]. Stress can negatively impact career satisfaction, fulfillment in interpersonal relationships and even personal safety (e.g. accidents at work) [5,20-22]. And stress associated with subtle forms of sexual harassment undermines women's performance within the workplace [23]. Scientists and physicians link chronic stress to a broad array of adverse health outcomes. For example, there is mounting evidence from the fields of health psychology and behavioral medicine that chronic stress is associated with increased obesity, cardiovascular diseases (e.g. high blood pressure), and upper respiratory infection, as well as disorders that lead to autoimmune disease (e.g. Crohn's, fibromyalgia, multiple sclerosis, endometriosis) and inflammatory disease (e.g. hepatitis, inflammatory bowel disease, rheumatoid arthritis and cancer). Many scientists and physicians explain the deleterious impact stress has on quality of life and identify stress as a partial explanation for why the leading cause of death among women in the United States is cardiovascular disease.

\section{Looking Inward for a Solution to the Paradox}

All this research tells us that capable, qualified women often experience the career climb differently than their male counterparts. As a group, women are less likely to be promoted to the highest levels and less likely to feel life satisfaction due to the competing demands on their time and mental energy. Very often, diversity programs and leadership initiatives aimed at promoting women in the workplace focus on removing external barriers and providing women with important leadership skill sets and networks they may not have attained. However, what if that is only part of the problem, as Sandburg asserts? And what if the solution requires more than pushing women to "lean-in"? What if part of what is holding women back is wired into personality and inner narrative? This would mean that a dimension of the solution must include examination of the individual's narrative identity and its role in workplace success and well-being. In this article, we will explain how and urge organizations interested in the retention and career advancement of women to explore new narrative personality psychology models to harness the investments they are already making in diversity \& inclusion, leadership training, talent development, and employee wellness.

\section{A New Frontier Discipline of Psychology: What is Narrative Personality Psychology?}

Let us start with the science, and it may sound familiar even if brand new to you.

Everyone has a story. Narrative personality psychologists are curious about how individuals develop an internal and evolving narrative of self, also known as their narrative identity [24-26]. From this perspective, identity itself is a curated life story [24,27].

\section{Narrative Identity Theory: Toward a New Theory of Change for Professional Women and Organizations}

\section{Narrative Identity is Malleable}

Narrative identity is a dimension of personality alongside personality traits (e.g. introversion) and personality characteristic adaptations (e.g. personal strivings, achievement motivation, emotional intelligence, psychological defenses, psychosocial tasks) [28]. Unlike other dimensions of personality that are relatively fixed across the life course, narrative identity is the most malleable personality dimension. Narrative identity answers core identity questions such as "who am I"? [29] and "how do I bring unity and purpose to my life? [30]. Narrative identity is so malleable because each of us has the psychological capacity to construct and reconstruct (or re-story) our narrative identity. This process of reconstruction - largely done through engaging various psychological systems within the brain - provides the psychological freedom to author narrative identity. The narrative processing of experience in storied form can tie together the psychological meaning of remembered past, perceived present, and anticipated future life experiences to provide life with a sense of unity and purpose that all humans crave [31,32]. Psychologists explain that narrative identity offers the person a sense of a personalized "niche" in the adult world, as well as a sense of continuity and sameness across situations and over time [31]. Starting in adolescence and extending across adulthood, individuals develop narrative identity through a process of constructing autobiographical memories from daily life experiences. Individuals make sense of self through an ongoing process of synchronic (e.g. across the many roles the person play in life) and diachronic (e.g. across the time of the life span) integration of life experiences with the goal of curating a coherent narrative identity [32]. Autobiographical memories are event specific, discrete, vivid, and emotionally salient. For example, an event-specific memory is a life experience that took place on a particular day (March 16) or very specific time (the moment I knew I wanted to spend the rest of my life with my boyfriend) rather than something that occurred over an extended period (e.g. my summer vacation). 
Narrative identity can be curated from autobiographical memories

Autobiographical memories undergird life-long identity formation because they become the substance from which the individual draws in curating his or her narrative identity. How does a person decide among all her experiences which will become remembered in the form of an autobiographical memory and incorporated into her inner narrative? There are three answers to this question. First, emotion is the key psychological system that deciphers which memories a person attends to, encodes, and retrieves. In other words, as Singer \& Salovey [33] explain in their book the Remembered Self: Emotion and Memory in Personality, emotions generated by events in the world determine what we pay attention to, what we try to record in detail and what we remember years later. Second, a person's basic psychosocial needs and goals across different periods of development drive the meaning a person derives from various experiences within autobiographical memories $[28,34]$.

i. During adolescence (ages 12-17), individuals have the psychosocial need to develop a sense of self and personal identity through exploration and autonomy with a special focus on social relationships. This can take the form of the natural and developmentally appropriate inclination for adolescents to explore different expressions of who they are and want to become interpersonally and socially, as well as to push for more choice in school contexts about classes, extracurricular activities, and friends.

ii. During emerging adulthood (i.e. ages 18-27) and early adulthood (i.e. ages 28-39) individuals have psychosocial needs for agency (e.g. control over their environment) and achievement. For example, within industrialized and Western countries like the United States, individuals during emerging adulthood and early adulthood are often striving to fulfill needs through exploration of a range of life goals (and values) linked to education, jobs, friendships, love, and marriage.

iii. During middle adulthood (i.e. ages 40-65), individuals have psychosocial needs for generativity, which is a need for connection, impact, and legacy. An individual fulfills this need to shape the well-being of the next generation through an iterative process of narrative reflection and narrative reconstruction. In this narrative processing, the person engages in narrative identity work in which they winnow down life goals to the most meaningful life experiences and values [31].

Finally, culture plays an important role in the development of narrative identity. As McAdams \& Pals [28] explain, "cultures provide a menu of stories for the life course and specify how stories should be told and lived. In modern societies, many different stories compete with each other. Persons must choose some stories and resist others" (p. 212). The role of culture in narrative identity within the workplace is particularly complex for individuals from minoritized groups [35-38]. For example, individuals from groups who experience systemic racism have to contend with an extra layer of psychological complexity in their narrative processing of daily life experiences and thus, their narrative identity development $[26,39]$. Likewise, women from all racial groups commonly experience sexism, sexual harassment, and other forms of workplace incivility [13]. Moreover, women of color are likely to experience gendered racism. For example, Morgan, Mayo \& Thomas [40] highlight research about the many forms that gendered racism takes and how it impacts African American women's workplace experiences, particularly in their ascension to leadership within business organizations. Authenticity is one of the highest virtues endorsed by individuals in the business world [41]. And yet, many workplace cultures penalize these minoritized individuals when they bring their whole selves to work, which can undermine identity development and its positive impact on health and well-being [40]. As a result of these types of experiences, minoritized women must expend intellectual and psychological energy engaging in complicated code switching and concealment of core dimensions of their identity. Ultimately their well-being and success in the workplace is often undermined and constrained. Moreover, in organizations with limited racial, gender, and/or sexual orientation diversity, leaders and co-workers often expect minoritized individuals to engage in diversity and inclusion work within the organization. And though the work may be described as mission critical, often it is not formalized as part of specific job descriptions, performance evaluations, and compensation [42]. Ultimately, this kind of work often creates additional burdens but limited professional and financial upside. It can also exacerbate women's chronic stress, thereby hampering job satisfaction and undermining retention efforts central to diversity programs. Given the stress created when one has to conceal or alter identity in order to succeed in the workplace, any effort to promote job satisfaction and well-being should examine narrative identity.

\section{The Strong Relationship Between Narrative Identity and Well-Being}

The way in which a person narrates matters. In a review of narrative identity studies, McAdams \& McLean [25] found that individuals who use certain kinds of themes in deriving personal meaning from autobiographical memories have better well-being. They discovered evidence across multiple studies that individuals who constructed inner stories with themes of redemption (e.g. turning the meaning of "bad" experiences to good) and themes of generativity (e.g. connection with others, concern for the next generation) experienced more life satisfaction, personal growth, and well-being. Generativity narrative identity themes tend to be more pronounced for individuals at life's midcourse compared to earlier stages of human development because the midcourse of 
life is a natural developmental inflection point to move away from stagnation.

The science tells us:

i. each of us has a life story that we can construct (or reconstruct) from an inner narrative

ii. the way we narrate our own life stories and weave together our own autobiographical memories can enhance our sense of well-being and satisfaction

iii. and this is particularly so in life's mid-course (40 - 65) which, for many, professional women coincides with peak career growth, earning potential and family demands.

\section{Narrative identity of women: It's complicated ....}

Narrative identity construction of women is complicated by several interlocking factors. The first is the superwoman archetype. Within U.S. popular culture, working women are often revered as super-human, someone who "does it all and does it all well" somehow effortlessly. She is often portrayed as perfectly balancing her home responsibilities and work obligations. This mythology creates a master narrative about women's lives and success that many women must psychologically negotiate in constructing their own unique inner narrative. For example, a professional woman answering the core identity questions "who am I"? (Erikson, 1968) and "how do I bring unity and purpose to my life? [30] often begins with society's master narrative script for her "I am a woman who has to do it all... ...do it well...and make it look easy."

The second factor complicating a professional women's narrative identity is that any perception she has that she has failed to live up to the superwoman archetype can create a dissonance that is psychologically unsatisfying. Her inner narrative may even replay a script something like...." though I am working super hard, I still am not meeting expectations (mine and others) of what I can and perhaps should be able to do." In addition, this kind of narrative identity complication can create a lonely psychological existence for some women because, as a form of coping, she has to adopt a mindset that she just has to "fake it 'til she makes it". This may be a variation on the imposter syndrome [14,43-44]. In other words, a woman with a narrative identity enveloped by a superwoman archetype may be burdened by an inner narrative that she is an imposter or a failure rather than an inner narrative that celebrates her success and achievements. Integrating the superwoman archetype into narrative identity construction comes with liabilities (relationship strain, stress-related health behaviors, and stress embodiment) and benefits (preservation of self and family or community) [45].

On the one hand, constructing an inner superwoman narrative that she is pursing a challenging career while maintaining an idyllic home life may provide some psychological fulfillment. On the other hand, we have seen that the pressure to do both well and at the same time leads to high stress levels and often low life satisfaction among women. The sheer physical and psychological load that many women assume daily while they undertake varied work and family responsibilities has costs in the form of chronic stress and psychological burden.

\section{Rewriting the Inner Narrative}

Organizations can provide education within professional development, leadership, and other employer training programs that enable women (and men) to understand the dimensions of personality. In so doing, organizations can support practices, programs, and policies that harness the power of their employees' inner narrative to promote well-being and success. Through narrative personality psychology education and training, women can learn more about the nature of the narrative identity dimension of their personality. Women can be educated as intelligent consumers of narrative personality psychology, with a special focus on their inner narrative. In so doing, women could learn about the features of the narrative structure of their narrative identity. These features include the reoccurring characters, ideological settings (e.g. worldviews), and narrative scripts.

Learning about the characters, for example, could allow women to understand the ways in which the superwoman archetype is intertwined with other features of their narrative identity impacting health and well-being. More specifically, women could be trained to use narrative personality tools to know when and how to restory their narrative identity archetypes and narrative scripts. This process would include replacing maladaptive interpretations of their narrative experiences with psychologically healthy alternatives. For example, the superwoman archetype places enormous pressure on the daily living of women. Many, for example, translate this pressure into a mandate to make choices to "live up" to the superwoman standard imposed on them within their families, communities, workplaces, and broader society. One way to think about this psychological processing from a narrative identity restorying perspective is that the superwoman archetype is an unnecessary "stress character" in many women's narrative identity that can undermine their wellbeing and success. What if women were armed with narrative personality tools that enabled them to supplant the superwoman archetype with an alternative? Imagine the positive impacts of a woman instead crafting a discerning woman archetype. For example, a discerning woman narrative celebrates her ability to go beyond the common strategy of prioritization. In so doing, when bombarded with an overflowing "to do list" a woman could use her new narrative identity archetype of the discerning woman to decipher which tasks could be executed only to the point of "good enough" and which tasks truly require her "excellence". This new archetype, in contrast to the superwoman archetype, could cultivate a healthier stress response, which would in turn promote her well being and success.

As was previously mentioned in describing narrative 
identity, certain narrative scripts promote health and well-being. And psychologists have discovered some narrative scripts are healthier than others because they align with a person's natural psychosocial needs at a particular stage of human development.

For example, research has demonstrated thematic lines of generativity within narrative identity fulfills the psychosocial need to avoid stagnation during life's midcourse. Similarly, narrative personality psychologists have shown how thematic lines of redemption during emerging adulthood and the midcourse support healthy narrative identity development and better overall well-being [46].

How do we know that this kind of narrative identity work is possible? Since narrative identity is authored by the individual, a person has the interpretive capacity as an autobiographical author to shift characters, themes, and emotional tone to derive what psychologists call integrative meaning. The process of creating integrative meaning involves that individual's work to take "a step back" [47] from culturally imposed self-definitions about who they are and what their life means. In so doing, individuals can do what is psychologically adaptive (i.e. works well for them) in the context of their overall life and specific situations as they reconstruct their narrative identity [48-55].

\section{Conclusion}

Within the United States, there are unprecedented numbers of corporate, academic, and non-profit organizations investing in diversity \& inclusion, leadership training, and employee wellness. Managers and executive level leaders who are responsible for establishing organizational goals, initiatives, and metrics for success in these areas of organizational development should become betteracquainted with contemporary narrative personality psychology models. These models emphasize the power of each person to be an autobiographical author and the architect of a stronger relationship between a person's inner narrative (i.e. narrative identity), well-being, and success. Organizations that invest in the application of narrative personality psychology to promote well-being and success will discover that they can contribute, like other approaches, to maximize women's talent and to expand the organization's effectiveness. Thus, narrative personality psychology can be good for the organization's bottom line and women's lives too!

\section{References}

1. Sandberg S (2013) Lean in: Women, work, and the will to lead. Random House.

2. Gibson C (2018) The end of leaning in: How Shery's Sandberg's message of empowerment fully unraveled. The Washington Post.

3. Ginder SA, Kelly-Reid JE, Mann FB (2018) Postsecondary Institutions and Cost of Attendance in 2017-18; Degrees and other awards conferred, 2016-17; and 12-Month enrollment, 2016-17: First look (Provisional Data). NCES 2018-060rev. National Center for Education Statistics.
4. Okahana H, Zhou E (2018) Graduate enrollment and degrees: 2007 to 2017. Washington, DC: Council of Graduate Schools.

5. (2018) U.S Bureau of Labor Statistics Highlights of women's earnings in 2018 (Publication No. Report 1083).

6. Settles IH, Cortina LM, Malley J, Stewart AJ (2006) The climate for women in academic science: The good, the bad, and the changeable. Psychology of Women Quarterly 30(1): 47-58.

7. Sousa-Poza, Alfonso, Sousa-Poza, Andres (2000) Well-being at work: A cross-national analysis of the levels and determinants of job satisfaction. The Journal of Socio-Economics 29(6): 517-538.

8. (2018) McKinsey \& Company \& LeanIn.org Women in the workplace.

9. Hewlett SA (2002) Executive Women and the Myth of Having it All. Harvard Business Review.

10. Salum M (2018) Does 'having it all mean' doing it all? The New York Times.

11. Rao AH (2019) Even breadwinning wives don't get equality at home. The Atlantic.

12. Ciciolla L, Luthar SS (2019) Invisible household labor and ramifications for adjustment: Mothers as captains of households. Sex Roles 81(7-8): 467-486

13. Cortina LM (2008) Unseen injustice: Incivility as modern discrimination in organizations. Academy of Management Review 33(1): 55-75.

14. Clance PR, Dingman D, Reviere SL, Stober DR (1995) Impostor phenomenon in an interpersonal/social context: Origins and treatment. Women \& Therapy 16(4): 79-96.

15. Heid M (2020) Rising to the challenge: From physical threats to emotional conflict, stress triggers a series of complex biochemical reactions in the body and mind. Special Times Edition: The Science of Stress.

16. Mwendwa DT, Sims RC, Madhere S, Thomas J, Keen LD (2011) The influence of coping with perceived racism and stress on lipid levels in African Americans. Journal of the National Medical Association, 103(7): 594-601.

17. Mwendwa DT, Gholson G, Sims RC, Levy-Massey SA, Ali M et al. (2011) Coping with perceived racism: A significant factor in the development of obesity in AfricanAmerican women? Journal of the National Medical Association, 103(7): 602-608.

18. Mwendwa DT, Ali M, Sims R, Madhere S, Levy S et al. (2013) Psychometric properties of the Cook Medley Hostility Scale and its association with inflammatory markers in African Americans. Psychology, Health, and Medicine 18(4): 431-444.

19. American Psychological Association (2019) Stress in America: Stress and Current Events. Stress in America ${ }^{T M}$ Survey.

20. Barber LK, Grawitch MJ, Maloney PW (2016) Work-life balance: Contemporary perspectives. In Grawitch MJ, DW Ballard (Eds.), The psychologically healthy workplace: Building a win-win environment for organizations and employees. American Psychological Association. p. 111-133.

21. Thompson MJ, Carlson DS, Kacmar KM, Vogel RM (2020) The cost of being ignored: Emotional exhaustion in the work and family domains. Journal of Applied Psychology 105(2): 186-195.

22. Damour L (2019) At ease: Reframing stress and anxiety. APA 2019 Convention, Chicago, IL, United States.

23. Woodzicka JA, LaFrance M (2005) The Effects of Subtle Sexual Harassment on Women's Performance in a Job Interview. Sex Roles 53: 67-77.

24. Singer JA (2004) Narrative Identity and Meaning Making Across the Adult Lifespan: An Introduction. Journal of Personality, 72(3): 437-460. 


\section{Annals of Social Sciences \& Management studies}

25. McAdams DP, McLean KC (2013) Narrative Identity. Current Directions in Psychological Science 22(3): 233-238.

26. Winston-Proctor CE (2018) Toward a model for teaching and learning qualitative inquiry within a core content undergraduate psychology course: Personality psychology as a natural opportunity. Qualitative Psychology 5(2): 243-262.

27. McAdams DP (1985) Power, Intimacy, and the Life Story: Personological Inquiries into Identity. Guilford Press, New York, United States.

28. McAdams DP, Pals JL (2006) A new Big Five: Fundamental principles for an integrative science of personality. American Psychologist 61(3) 204-217.

29. Erikson EH (1968) Identity: Youth and crisis. New York: Norton.

30. McAdams DP (1995) What do we know when we know a person? Journal of Personality 63(3): 365-396.

31. McAdams DP, Hart HM, Maruna S (1998) The anatomy of generativity: How and why we care for the next generation. In McAdams DP, Aubin E (Eds.), Generativity and adult development: How and why we care for the next generation American Psychological Association Press.

32. McAdams DP (2001) The psychology of life stories. Review of Genera Psychology 5(2): 100-122.

33. Singer JA, Salovey P (1993) The remembered self: Emotion and memory in personality. Free Press.

34. McAdams DP (2015) The art and science of personality development. Guilford Press, New York, United States.

35. Evans L, Moore WL (2015) Impossible burdens: White institutions, emotional labor, and micro resistance. Social Problems, 62(3): 439454

36. Ragins BR (2004) Sexual orientation in the workplace: The unique work and career experiences of gay, lesbian and bisexual workers. In Martocchio JJ (Ed.), Research in personnel and human resources management. Research in personnel and human resources management 23: $35-129$

37. Hill RJ (2009) Incorporating Queers: Blowback, Backlash, and Other Forms of Resistance to Workplace Diversity Initiatives That Support Sexual Minorities. Advances in Developing Human Resources 11(1): 37-53.

38. Zurbrügg L, Miner KN (2016) Gender, sexual orientation, and workplace incivility: Who is most targeted and who is most harmed? Frontiers in Psychology 7: 1-12.

39. Winston CE, Winston MR (2012) Cultural psychology of racial ideology in historical perspective: An analytic approach to understanding racialized societies and their psychological effects on lives. In Valsiner (Edn.), Oxford Handbook of Culture and Psychology New York: Oxford University Press pp. 559-581.
40. Roberts LM, Mayo AJ, Thomas DA (2019) Race, work, and leadership: New perspectives on the black experience. Harvard Business Press.

41. Ménard J, Brunet L (2011) Authenticity and well-being in the workplace: a mediation model. Journal of Managerial Psychology 26(4): 331-346.

42. McKay PF, Avery DR (2005) Warning! Diversity recruitment could backfire. Journal of Management Inquiry 14(4): 330-336.

43. Clance PR, Imes SA (1978) The imposter phenomenon in high achieving women: Dynamics and therapeutic intervention. Psychotherapy: Theory, Research \& Practice 15(3): 241-247.

44. Chrisman SM, Pieper WA, Clance PR, Holland CL, Glickauf-Hughes C (1995) Validation of the Clance Imposter Phenomenon Scale. Journal of Personality Assessment 65(3): 456-467.

45. Woods-Giscombé CL (2010) Superwoman Schema: African American Women's Views on Stress, Strength, and Health. Qualitative Health Research, 20(5): 668-683.

46. Singer JA, Blagov P, Berry M, Oost KM (2013) Self-Defining Memories, Scripts, and the Life Story: Narrative Identity in Personality and Psychotherapy: Healthy Narrative Identity. Journal of Personality 81(6): 569-582.

47. Singer JA (2005) Personality and psychotherapy: Treating the whole person. Guilford Press.

48. Acker J (2006) Inequality regimes: Gender, class, and race in organizations. Gender \& Society. 20(4): 441-464.

49. American Medical Association (2019) Medical education facts: Applicants and matriculants data.

50. Anxiety and Depression Association of America (2006) Highlights: Workplace stress and anxiety disorders survey.

51. Erikson EH (1963) Childhood and society (2 ${ }^{\text {nd }}$ edn.), New York: Norton.

52. McAdams DP (1988) Power, intimacy and the life story. Guilford Press New York, United States.

53. McAdams DP, Manczak E (2011) What is a "level" of personality? Psychological Inquiry 22(1): 40-44.

54. Mwendwa DT, Ali MK, Sims RC, Cole AP, Lipscomb MW et al. (2013) Dispositional depression and hostility are associated with inflammatory markers of cardiovascular disease in African Americans. Brain, Behavior, and Immunity 28: 72-82.

55. Smith AE, Hassan S, Hatmaker DM, DeHart-Davis, L, Humphrey N (2020) Gender, Race, and Experiences of Workplace Incivility in Public Organizations. Review of Public Personnel Administration.

\begin{tabular}{l} 
Your next submission with Juniper Publishers \\
will reach you the below assets \\
- Quality Editorial service \\
- Swift Peer Review \\
- Reprints availability \\
- E-prints Service \\
- Manuscript Podcast for convenient understanding \\
- Global attainment for your research \\
- Manuscript accessibility in different formats \\
( Pdf, E-pub, Full Text, Audio) \\
- Unceasing customer service \\
Track the below URL for one-step submission \\
https://juniperpublishers.com/online-submission.php \\
\hline
\end{tabular}

